УДК 330

\title{
ПОНЯТИЕ ЭКОНОМИКИ И ФАКТОРЫ, ВЛИЯЮЩИЕ НА ЭКОНОМИЧЕСКУЮ СОСТАВЛЯЮЩУЮ ЛЮБОГО ПРОЕКТА, ПРЕДПРИЯТИЯ И ГОСУДАРСТВА
}

\author{
Зенкина Дарья Вячеславовна \\ магистр, ведущий экономист \\ ФГУП «ФЦДТ «Союз» \\ Рогожина Наталья Вячеславовна \\ экономист, начальник бюро по ТЭП \\ ФГУП «ФЦДТ «Союз»
}

\begin{abstract}
Аннотация: Целью статьи является разбор понятия «экономика» с акцентом на экономическую деятельность. Рассмотрены составляющие экономической деятельности. Также акцентируется внимание на причинах краха и неэффективности экономических решений, основанных на политическом влиянии, недостатке доверия и недостатке компетенции вышестоящих управленцев.
\end{abstract}

Ключевые слова: экономика, экономическая деятельность, государство, доверие, капитализм, политика, экономическая эффективность.

\section{THE CONCEPT OF ECONOMY AND THE FACTORS INFLUENCING THE ECONOMIC COMPONENT OF ANY PROJECT, ENTERPRISE AND STATE}

\section{Zenkina Darya Vyacheslavovna Rogozhina Natalia Vyacheslavovna}

\begin{abstract}
The purpose of the article is to analyze the concept of "economy" with an emphasis on economic activity. The components of economic activity are considered. Attention is also focused on the causes of the collapse and inefficiency of economic decisions, basing on political influence, lack of trust and lack of competence of higher managers.
\end{abstract}

Key words: economy, economic activity, states, trust, capitalism, politics, 


\section{НОВАЯ НАУКА В НОВОМ МИРЕ: ФИЛОСОФСКОЕ, \\ СОЦИАЛЬНО-ЭКОНОМИЧЕСКОЕ, КУЛЬТУРОЛОГИЧЕСКОЕ ОСМЫСЛЕНИЕ}

economic efficiency.

Рассматривая различные подходы к определению экономики, многие замечают тот факт, что экономика затрагивает все сферы жизни. Таким образом, кажется, что экономика изучает устройство всей жизни. Однако стоит все-таки ограничить понимание экономики в рамках изучения экономической деятельности. Вопросы, которые касаются данного предмета, относятся к рассмотрению таких составляющих, как деньги, труд (работа), технологии, международная торговля, налоги и прочие аспекты, которые затрагивают производство товаров и услуг, распределение и потребление различных благ.

Говоря об экономике, первом делом всегда говорят о деньгах. Деньги это средство и символ экономической деятельности. Одним из самых распространенных способов получения денег - это работа. Таким образом, многие вопросы экономики непосредственно касаются работы. Рассматривая, что понимается под работой с точки зрения даже одного человека, выясняется, что знания должны касаться таких понятий, как навыки, технологические инновации и международная торговля. Оценивая работу, на сегодняшний день все задаются вопросами заработной платы и условий труда, которые, в свою очередь, имеют огромную зависимость от политических решений. Например, принятие ограничений в конце XIX - начале XX веков по применению детского труда привело к сжатию рынка труда. Менее радикальным примером влияния политических решений на экономическую составляющую является принятие положений о продолжительности рабочего дня, минимальном размере оплаты труда и условиях труда. Таким образом, замечено огромное влияние политики на экономику.

Продолжая дальше рассматривать предмет изучения экономики, после понимания работы и зарабатывания денег переходим к вопросу потребления. То есть для экономистов важно изучать вопросы распределения денег, товаров и услуг. Так же важно понимать каким образом люди выбирают из конкурирующих товаров и услуг, как влияет на их выбор реклама, как влияет имидж компании на траты людей и как траты, которые несут компании на создание этого имиджа, влияют на их прибыль.

Но чтобы любые товары и услуги использовать и распределять, необходимо их произвести. Таким образом, производство представляет собой основание любой экономической деятельности. Ведь, как правило, наиболее мощные социальные преобразования происходят в сфере производства. 


\section{НОВАЯ НАУКА В НОВОМ МИРЕ: ФИЛОСОФСКОЕ, \\ СОЦИАЛЬНО-ЭКОНОМИЧЕСКОЕ, КУЛЬТУРОЛОГИЧЕСКОЕ ОСМЫСЛЕНИЕ}

В то время как вопросы производства представляют собой огромное количество рутинных дел.

Как видно из выше изложенного, экономика рассматривает большой спектр вопросов, которые возникают при взаимодействии людей. Т.е. экономические вопросы, которые люди пытаются решить, возникли из-за того, что большое количество людей объединились сначала в государства, а затем и переплелись на мировом уровне, таким образом, что любая экономическая деятельность отдельного человека, может влиять на состояние мирового экономического рынка. А значит, чтобы решать экономические вопросы, необходимо понимать взаимосвязь экономики и государства.

Стоит отметить, что ни одно общество в истории человечества не обходилось без государства. Именно оно устанавливает законы и гарантирует их соблюдение. Тем не менее, люди испокон веков задаются вопросом о роли государства - его функциях, полномочиях и пределах власти над отдельной личностью.

В XIX веке многие считали, что роль государства следует свести к поддержанию правопорядка в стране и защите от внешней агрессии. Как гласит классическая теория либерализма, «чем меньше государство управляет, тем оно лучше». Однако в наше время государству приходится регулировать экономические, социальные и экологические условия жизни общества.

Современное «государство всеобщего благоденствия» играет важную роль в жизни людей, обеспечивая их широким спектром социальных услуг. Под эту характеристику попадают многие страны, но не потому, что государство всем гарантирует социальную защиту, а потому, что оно в первую очередь помогает тем, кто остался без работы или пострадал от стихийных бедствий.

При этом, по данным социологических исследований, чтобы организовать любую деятельность человека, подчинить ее одним правилам и одним и тем же целям без официального принятие различных законам, существует критический порог размера группы в 150 человек [1, с. 38]. Размер любых социальных групп, будь то компании, общественные организации, военные представительства, государства, в таком случае обеспечивает выполнение любых действий согласовано на основе близкого знакомства и вере в общие цели. Однако при большем размере взаимодействия людей возникает потребность в формальной иерархии и правилах подержания порядка. Таким образом, доказано, что любое 


\section{НОВАЯ НАУКА В НОВОМ МИРЕ: ФИЛОСОФСКОЕ, \\ СОЦИАЛЬНО-ЭКОНОМИЧЕСКОЕ, КУЛЬТУРОЛОГИЧЕСКОЕ ОСМЫСЛЕНИЕ}

человеческое сотрудничество в широком масштабе - от предприятия до государства и мирового сообщества - вырастает из общих мифов, правил, законов и прочих вещей, которые существуют в головах людей. Т.е. любые действующие законы, как экономические, так и общеправовые действуют в пределах того общества, где все приняли их за основу и верят в их исполнимость, правдивость, справедливость и т.д.

Так, анархисты, считающие государство источником всех бед, убеждены, что регулировать жизнь общества должны отдельные личности и ассоциации производителей. В XIX веке они пытались свергнуть не одно правительство, прибегая к террору и саботажу, и на их совести убийства многих государственных лидеров, в том числе президента США У. Мак-Кинли.

Антипод анархизма - тоталитарный или авторитарный режим - ставит под контроль все сферы жизни отдельных граждан и общества в целом, требуя безусловного подчинения и пресекая всякое инакомыслие. Форма правления, при которой верховная власть сосредоточена в руках одного человека, называется диктатурой или абсолютной монархией. Если же государством правит небольшая группа лиц, то мы говорим об олигархии.

Золотую середину занимают плюралистические и либеральные общества, где на равных правах существуют государственные и частные формы правления, оказывая друг на друга взаимное влияние. Плюралистические системы ставят во главу угла свободу личности, налагая ряд ограничений на полномочия органов власти.

Некоторые страны отдают предпочтения социализму, при котором базовые отрасли экономики и социальное обеспечение находятся под контролем государства. Иные же, следуя по капиталистическому пути, отдают львиную долю индустрии и сферы услуг в руки частных предпринимателей.

Почти каждая страна имеет свою конституцию - основной закон, управляющий жизнью общества. Великобритания единственная из современных государств не имеет записанной конституции. Вместо нее на основе старинных статутов, включая Великую хартию вольностей, судебных решений, парламентских законов, традиций и обычаев, в стране действуют правила, определяющие круг полномочий и обязанностей органов государственной власти.

Рассматривая современную модель государственного устройства, стоит заметить преобладание капитализма во всем мире. Реалии современной эпохи 


\section{НОВАЯ НАУКА В НОВОМ МИРЕ: ФИЛОСОФСКОЕ, \\ СОЦИАЛЬНО-ЭКОНОМИЧЕСКОЕ, КУЛЬТУРОЛОГИЧЕСКОЕ ОСМЫСЛЕНИЕ}

дают понять, что капитализм, как современная экономическая модель исчерпала себя. К такому выводу в ноябре 2021 года на заседании клуба «Валдай» пришел президент Российской Федерации В.В. Путин.

«Все говорят о том, что существующая модель капитализма, а это сегодня основа общественного устройства в подавляющем большинстве стран, исчерпала себя. В ее рамках нет больше выхода из клубка все более запутанных противоречий» [9], - сказал он.

Президентом РФ было замечено, что даже богатые страны неравномерно распределяют материальные блага и усугубляют неравенство еще сильнее, особенно в период пандемии. Было замечено, что на сегодняшний день стоит пересмотреть и оценить существующую экономическую деятельность.

Рассматривая капиталистический рынок, вспомним пример побежденной и оккупированной Японии, которая через 10 лет после окончания II мировой войны восстановила свою промышленность и ступила в период беспрецедентного роста, благодаря которому стала экономическим гигантом. Чертой, которая отличала в то время экономику Японии от других стран, было сочетание капиталистического свободного рынка с активной ролью государства. Благодаря этому, были созданы условия для более легкого развития промышленности с возможностью проведения долгосрочного планирования развития. Японцы были преданы и доверяли своему правительству. При этом рынок не полностью был под контролем государства, оставляя возможность развитию капиталистического свободного рынка. Таким образом, пример Японии показывает, как при взаимосвязи такое большого количества людей (намного больше 150 человек) могут прийти к экономическому успеху, опираясь не только на знания и цифры, но и огромное доверие на все принятые правительством меры.

Рассматривая современное состояние в России, заметим наличие стагнации экономики. В данном случае огромное влияние оказывает неспособность системы управления реагировать на современные вызовы, а также неспособность принимать эффективные стратегические решения руководителей всех уровней. Причиной неэффективности или краха большинства экономических проектов в России является преобладание политического влияния на экономические и социальные аспекты, при отсутствии профессионально подготовленных лиц, принимающих решения, и доверия к принятым решениям, а также наличие несогласованности 


\section{НОВАЯ НАУКА В НОВОМ МИРЕ: ФИЛОСОФСКОЕ, \\ СОЦИАЛЬНО-ЭКОНОМИЧЕСКОЕ, КУЛЬТУРОЛОГИЧЕСКОЕ ОСМЫСЛЕНИЕ}

принимаемых решений и проектов со всеми заинтересованными участниками рынка.

Таким образом, подмечена прямая зависимость между доверием и экономическим успехом. Примером того, как недоверие сказалось на экономическую обстановку, является состояние экономики в СССР в конце 80-ых годов, когда было сильное снижение благосостояния советских граждан и заметное уменьшение ВВП страны. Изучая зарубежную литературу, найдется много доказательств того, как доверие и социальный капитал ведут к увеличению темпов прироста экономики.

На сегодняшний день во всем мире наблюдается кризис доверия (рис.1.) [10]. Во многих развитых и развивающихся странах уровень доверия за последний год значительно понизился.

\begin{tabular}{l|c|c}
\hline Government & $\begin{array}{c}+/ \text { Jan } 2020 \text { to } \\
\text { May 2020 }\end{array}$ & $\begin{array}{c}+- \text { May 2020 to } \\
\text { Jan 2021 }\end{array}$ \\
\hline S. Korea & +16 & -17 \\
\hline UK & +24 & -15 \\
\hline China & +5 & -13 \\
\hline Mexico & +12 & -12 \\
\hline Canada & +20 & -11 \\
\hline India & +6 & -8 \\
\hline U.S. & +9 & -6 \\
\hline Germany & +19 & -5 \\
\hline Japan & -5 & -1 \\
\hline Saudi Arabia & +5 & -1 \\
\hline France & +13 & +2 \\
\hline
\end{tabular}

\section{Рис. 1. Индекс доверия (11 стран, включенных в весеннее обновление Барометра доверия 2020 года) [10]}

Конечно, заметно, что на фоне пандемии, из-за которой многим правительствам приходится вводить затяжные ограничения при наблюдении ухудшения ситуации, большинство населения стало не доверять проводимым действиям и транслируемой информации. Как уже было замечено, что общество объединяет государство в лице правительства, то естественно, что основным вопросом несостоятельности любого принимаемого ими 


\section{НОВАЯ НАУКА В НОВОМ МИРЕ: ФИЛОСОФСКОЕ, \\ СОЦИАЛЬНО-ЭКОНОМИЧЕСКОЕ, КУЛЬТУРОЛОГИЧЕСКОЕ ОСМЫСЛЕНИЕ}

экономического действия является некомпетентность предсказать, как будет реагировать народ, при наличии недоверия граждан к государственным решениям.

В итоге стоит заметить, что группа людей более 150 человек (как было сказано ранее) может эффективно взаимодействовать, в том числе и экономически, только при наличии общих законов, мифов, правил, в которые верят люди, принимающие участие в этих проектах. Таким образом, наличие в обществе необходимых нормативно-правовых документов постепенно создает пространство для поддержки доверия и эффективного выполнения поставленных задач с возможность долгосрочного планирования.

Подытожив сказанное, можно сделать вывод о том, что экономика решает огромное количество вопросов, связанных с экономической деятельностью. В результате чего замечено огромное политическое влияние на любой экономический вопрос. При этом эффективность принятия экономического решения во взаимосвязи с политикой зависит от компетенции вышестоящих управленцев как компании, так и государства, и наличия доверия со стороны людей.

\section{Список литературы}

1. Харари Ю.Н. Sapiens. Краткая история человечества. М.: Синдбад, 2021 .

2. Ха-Джун Чанг Как устроена экономика. М.: Манн, Иванов и Фербер, 2014.

3. Маршалл. А. Принципы экономической науки. Изд. «Прогресс». 1993.

4. Смит А. Исследование о природе и причинах богатства народов. М.: Издательская группа «АСТ», 2019.

5. Бахтигараева А.И., Ставинская А.А. Сможет ли доверие стать фактором роста экономики? Динамика уровня доверия у российской молодежи // Вопросы экономики 2020 № 7 С. 92-107.

6. Зайцев А.Г., Полторыхина С.В., Ампилов И.С., Машегов П.Н. Институт доверия - фактор регионализации в современном мире // Евразийский юридический журнал, 2020 № 1 С. 407-409.

7. Полюшкевич О.А. Доверие в меняющемся мире // Социология, 2021 № 2 C. $87-92$. 


\section{НОВАЯ НАУКА В НОВОМ МИРЕ: ФИЛОСОФСКОЕ, СОЦИАЛЬНО-ЭКОНОМИЧЕСКОЕ, КУЛЬТУРОЛОГИЧЕСКОЕ ОСМЫСЛЕНИЕ}

8. Хусаинова А.И. Доверие к деньгам: проблемы содержательного определения // Вестник экономики, права и социологии, 2020 № 2 С. 39-41.

9. Путин заявил об исчерпании современной модели капитализма // Новости дня в России и мире URL: https://www.rbc.ru/economics/ 21/10/2021/617182b79a7947da0cfe221a (дата обращения: 25.10.2021).

10. Edelman trust barometer $2021 / /$ Welcome to Edelman URL: https://www.edelman.com/sites/g/files/aatuss191/files/2021-01/2021-edelman-trustbarometer.pdf (дата обращения: 14.10.2021).

(C) Д.В. Зенкина, Н.В. Рогожина, 2021 